九州大学学術情報リポジトリ

Kyushu University Institutional Repository

\title{
Influence of Pore Size and Surface Functionality of Activated Carbons on Adsorption Behaviors of Indole and Amylase
}

Miyawaki, Jin

Institute for Materials Chemistry and Engineering, Kyushu University | Interdisciplinary Graduate School of Engineering Sciences, Kyushu University

Yeh, Joonyoung

Interdisciplinary Graduate School of Engineering Sciences, Kyushu University

Ki l, Hyun-Sig

Interdisciplinary Graduate School of Engineering Sciences, Kyushu University

Lee, Jihn-Koo

PureSphere Co., Ltd

他

https://doi.org/10.5109/1800868

出版情報: Evergreen. 3 (2)，pp.17-24，2016-09. Green Asia Education Center バージョン：

権利関係 : 


\title{
Influence of Pore Size and Surface Functionality of Activated Carbons on Adsorption Behaviors of Indole and Amylase
}

\author{
Jin Miyawaki ${ }^{1,2,}$, Joonyoung Yeh $^{2}$, Hyun-Sig Kil², Jihn-Koo Lee ${ }^{3}$, \\ Koji Nakabayashi ${ }^{1,2}$, Isao Mochida ${ }^{4}$, Seong-Ho Yoon ${ }^{1.2 . *}$ \\ ${ }^{1}$ Institute for Materials Chemistry and Engineering, Kyushu University, 6-1 Kasuga-koen, \\ Kasuga, Fukuoka 816-8580, Japan. \\ ${ }^{2}$ Interdisciplinary Graduate School of Engineering Sciences, Kyushu University, 6-1 \\ Kasuga-koen, Kasuga, Fukuoka 816-8580, Japan. \\ ${ }^{3}$ PureSphere Co., Ltd., 545 Yongsan-dong, Yuseong-gu, Daejeon 305-500, Korea. \\ ${ }^{4}$ Kyushu Environmental Evaluation Association, 1-10-1 Mathukadai Higashiku, Fukuoka, \\ Fukuoka 813-0004, Japan. \\ *Author to whom correspondence should be addressed, \\ E-mail: miyawaki@cm.kyushu-u.ac.jp (J.M.),yoon@cm.kyushu-u.ac.jp (S.Y.)
}

(Received June 26, 2016; accepted September 21, 2016)

\begin{abstract}
Influence of pore size and surface functionality of activated carbons on liquid-phase molecular adsorption behaviors was carefully investigated both in terms of adsorption capacity and kinetics using indole and amylase as model adsorptive bio-materials by individual single-component experiments to improve adsorptive removal efficiency and selectivity of body wastes. Activated carbon fibers having narrow pore size of about $0.65 \mathrm{~nm}$ showed the highest adsorption capability of indole per unit surface area. From the point of view of the adsorption rate, however, a little bit wider micropores of about $0.70 \mathrm{~nm}$ considered to be preferable. It was also confirmed that a presence of oxygen-containing surface functional groups induces diffusional inhibitions of indole molecules to deeper pore spaces, giving rise to a lowering both of adsorption capacity and rate of indole. On the other hand, amylase adsorption amount was limited for microporous carbons. Therefore, as for oral applications to selectively remove the wastes in the body such as indole but not for useful molecules such as amylase, the activated carbons having abundant micropores of about $0.7 \mathrm{~nm}$ in size and hydrophobic surfaces were found to be suitable from the individual single-component experiments.
\end{abstract}

Keywords: Activated carbon, Adsorption, Bio-molecule, Pore size, Surface functionality

\section{Introduction}

One of functions of kidneys is to remove body wastes and poisonous substances. However, once gets sick and renal functions fail, it becomes hard to excrete the wastes from the body. Thus, an introduction of an artificial dialysis is required to excrete the wastes from the body, although it imposes mental and economic burdens on patients.

Carbon materials have been studied to be clinically used as a potent adsorbent of various toxic matters, thus, are called as medicinal carbons ${ }^{1-3)}$. It has been also reported to apply the medicinal carbons to remove waste products accumulated in the body as a result of chronic kidney diseases ${ }^{4-6}$. Furthermore, a kind of activated carbons, oral activated carbon (OAC), has been recently developed and commercialized for delaying the time of the artificial dialysis institution ${ }^{7}$. OAC which works by a principle of selective physical adsorption can adsorb the body wastes and poisonous substances during traveling in the body, and then to be excreted. One of advantages of OAC is that it absorbs vicious materials but not the requisite digestive enzymes for humans. However, its large required dosage, six grams per day, makes it hard to be administered routinely, and some of patients taking OAC have constipation ${ }^{8,9)}$. Therefore, it is necessary to minimize the patients' burdens with taking a small quantity for getting sufficient medicinal effects by developing activated carbon materials with higher adsorbability and selectivity.

In this study, we examined influence of pore size, surface functionality, and size of the activated carbons on 
the molecular adsorption behaviors to improve the adsorption capacity and selectivity for the body waste removals using indole and amylase as model adsorptive bio-materials by individual single-component experiments.

\section{Experimental}

\subsection{Samples}

Indole and a-amylase (Termamyl 120L equivalent) were purchased from Wako Pure Chemical Industries, Ltd., and used without further purification. Here, indole and amylase were selected as representative molecules to be removed (toxin) or not to be removed (enzyme), respectively. As the activated carbons, pitch-based activated carbon fibers (OG series: OG5A, OG7A, OG10A, OG15A, and OG20A, Osaka Gas Co., Ltd.) were used in this study, because they have relatively uniform micropores of different average pore size ${ }^{10)}$. To investigate an influence of surface functionalities on the adsorption behavior, most parts of oxygen-containing functional groups were removed by heat-treatments of OG series carried out in an $\mathrm{H}_{2}$ flow $\left(100 \mathrm{~cm}^{3} / \mathrm{min}\right)$ at 873 $\mathrm{K}$ for $1 \mathrm{~h}$. The $\mathrm{H}_{2}$-treated samples were designated as having " $\mathrm{H}_{2}-$ " as a prefix. A commercialized spherical oral activated carbon (OAC) of 200-300 $\mu \mathrm{m}$ in particle diameter and another type of a spherical activated carbon
(SAC, PureSphere Co., Ltd.) of 100-200 $\mu \mathrm{m}$ in particle diameter were also used. Pore structural parameters calculated from $a_{\mathrm{s}}$-plot analysis ${ }^{11,12)}$ of $\mathrm{N}_{2}$ adsorption isotherms at $77 \mathrm{~K}$ together with oxygen content, $0_{\text {diff., }}$, estimated from elemental analysis of all samples used in this study are summarized in Table 1.

\subsection{Adsorption measurements}

Adsorption tests of indole and amylase were carried out as follows. First, aqueous solutions of indole or amylase were prepared by dissolving indole or amylase in purified water at desired initial concentrations (0.001-0.004 wt.\% for indole and 2.6 vol.\% for amylase). Then, $8 \mathrm{mg}$ of each porous carbon sample was dispersed in the solution $\left(40 \mathrm{~cm}^{3}\right)$, and stirred for desired adsorption periods $(3 \mathrm{~min} \sim 96 \mathrm{~h}$ ) at $298 \mathrm{~K}$. After the set time passed, the porous carbon samples were filtered out by using a $0.20 \mu \mathrm{m}$ membrane filter, and then absorption spectra of the filtrates were measured by using an UVvisNIR spectrometer (UV3600, Shimadzu). Concentrations of indole or amylase in the filtrates were calculated from absorbance at $269 \mathrm{~nm}$ or $279 \mathrm{~nm}$, the maximum absorption wavelength of indole or amylase, respectively, using pre-measured calibration curves. Experimental errors of the adsorption tests of indole or amylase were estimated to be within $5 \%$.

Table 1. Pore structural parameters calculated from $\mathrm{a}_{\mathrm{S}}$-plot analysis of $\mathrm{N}_{2}$ adsorption isotherms at $77 \mathrm{~K}$ and oxygen content estimated from elemental analysis of activated carbon fibers and spherical activated carbons.

\begin{tabular}{|c|c|c|c|c|c|c|c|c|c|c|}
\hline \multirow{2}{*}{ Sample } & \multicolumn{4}{|c|}{ Specific surface area $\left(\mathrm{m}^{2} / \mathrm{g}\right)$} & \multicolumn{3}{|c|}{ Pore volume $\left(\mathrm{cm}^{3} / \mathrm{g}\right)$} & \multicolumn{2}{|c|}{$\begin{array}{l}\text { Average pore } \\
\text { size }(\mathrm{nm})\end{array}$} & \multirow{2}{*}{$\begin{array}{c}\text { Oxygen } \\
\text { content, } \\
0_{\text {diff. }} \text { b } \\
\text { (wt. } \% \text { ) }\end{array}$} \\
\hline & $A_{\text {total }}{ }^{a}$ & $A_{e x t}{ }^{a}$ & $A_{\text {micro }}{ }^{a}$ & $A_{\text {meso }}{ }^{a}$ & $\mathrm{~V}_{\text {total }}{ }^{\mathrm{a}}$ & $\mathrm{V}_{\text {micro }}{ }^{\mathrm{a}}$ & $V_{\text {meso }}{ }^{a}$ & $\mathrm{~W}_{\text {micro }}{ }^{\mathrm{a}}$ & $\mathrm{d}_{\text {meso }}{ }^{a}$ & \\
\hline $\mathrm{H}_{2}$-OG5A & 728.4 & 0.4 & 728.0 & - & 0.24 & 0.24 & - & 0.65 & - & 6.0 \\
\hline $\mathrm{H}_{2}-\mathrm{OG} 7 \mathrm{~A}$ & 1246.7 & 0.1 & 1246.6 & - & 0.44 & 0.44 & - & 0.70 & - & 5.2 \\
\hline $\mathrm{H}_{2}-\mathrm{OG} 10 \mathrm{~A}$ & 1305.0 & 0.3 & 1304.7 & - & 0.49 & 0.49 & - & 0.75 & - & 4.5 \\
\hline $\mathrm{H}_{2}-\mathrm{OG} 15 \mathrm{~A}$ & 1548.6 & 0.3 & 1548.3 & - & 0.71 & 0.71 & - & 0.91 & - & 2.5 \\
\hline $\mathrm{H}_{2}-\mathrm{OG} 20 \mathrm{~A}$ & 1802.1 & 0.5 & 1801.6 & - & 1.00 & 1.00 & - & 1.11 & - & 2.6 \\
\hline OG5A & 646.3 & 0.3 & 646.0 & - & 0.21 & 0.21 & - & 0.65 & - & 14.3 \\
\hline OG7A & 982.6 & 0.3 & 982.3 & - & 0.33 & 0.33 & - & 0.68 & - & 19.0 \\
\hline OG10A & 1283.2 & 0.1 & 1283.1 & - & 0.47 & 0.47 & - & 0.74 & - & 22.2 \\
\hline OG15A & 1688.3 & 0.3 & 1688.0 & - & 0.76 & 0.76 & - & 0.90 & - & 12.8 \\
\hline OG20A & 1928.3 & 0.3 & 1928.0 & - & 1.07 & 1.07 & - & 1.11 & - & 12.1 \\
\hline OAC & 1586.4 & 1.4 & 1585.0 & - & 0.76 & 0.76 & - & 0.96 & - & 4.7 \\
\hline SAC & 1316.1 & 6.6 & 1253.8 & 55.7 & 0.77 & 0.44 & 0.33 & 0.69 & 12 & 15.1 \\
\hline
\end{tabular}

${ }^{a} A_{\text {total }}, A_{\text {ext }}, A_{\text {micro, }}$ and $A_{\text {meso }}$ denote specific surface areas of total, external, micropores, and mesopores, respectively. $V_{\text {total }}, V_{\text {micro, }}$ and $V_{\text {meso }}$ are total, micropore, and mesopore volumes, respectively. $W_{\text {micro }}$ and $d_{\text {meso }}$ denote micropore width and mesopore diameter, respectively.

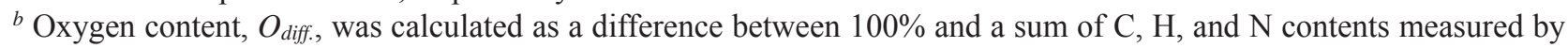
elemental analysis according to the following equation: $\mathrm{O}_{\text {diff. }}=100-(\mathrm{C}+\mathrm{H}+\mathrm{N})$. 


\section{Results and Discussion}

Figure 1 shows adsorption kinetic profiles of indole at $298 \mathrm{~K}$ for the $\mathrm{H}_{2}$-OG series with low oxygen contents at different initial concentrations of indole from 0.001 to 0.004 wt.\%. Here, the abscissa is shown in a logarithmic scale. When the initial concentration of indole was high, the longer equilibrium period was needed. The narrower the pore size, the slower the adsorption rate; $\mathrm{H}_{2}$-OG5A of very narrow pore size, $\mathrm{W}_{\text {micro }}=0.65 \mathrm{~nm}$, showed much slower adsorption rate as compared to others. For equilibrium adsorption amounts of indole, no remarkable difference was observed among 5 kinds of the $\mathrm{H}_{2}-\mathrm{OG}$ series samples when the initial concentration was low. For example, at 0.001 or 0.002 wt. $\%$ of the initial concentration, removal efficiencies of indole, calculated as an adsorption amount of indole normalized by the initial amount of indole in the solution, were more than $98 \%$ regardless of samples used. At higher initial concentration (e.g. 0.004 wt.\%), however, equilibrium adsorption amount of indole for $\mathrm{H}_{2}$-OG5A was remarkably lower than others, because of the limited pore volume of $\mathrm{H}_{2}-\mathrm{OG} 5 \mathrm{~A}\left(\mathrm{~V}_{\text {total }}=\mathrm{V}_{\text {micro }}=0.24 \mathrm{~cm}^{3} / \mathrm{g}\right)$.

Adsorption isotherms of indole at $298 \mathrm{~K}$ on the $\mathrm{H}_{2}-\mathrm{OG}$ series are shown in Figure 2. Steep adsorption uptakes of indole were observed from very low concentration.
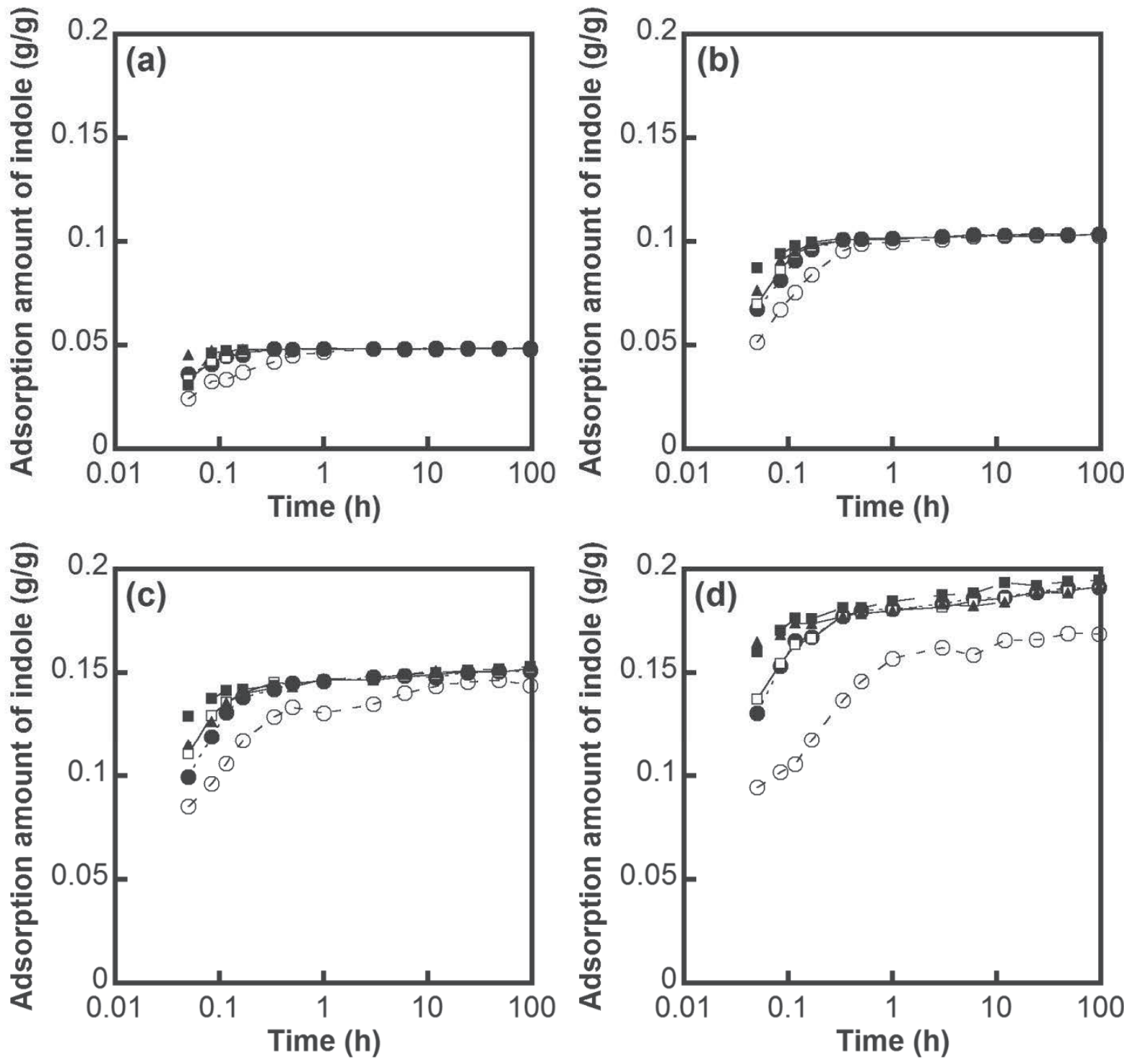

Fig. 1. Adsorption kinetic profiles of indole for $\mathrm{H}_{2}-\mathrm{OG}$ series at (a) $0.001 \mathrm{wt} . \%$, (b) 0.002 wt.\%, (c) 0.003 wt. $\%$, and (d) 0.004 wt. $\%$ of initial concentrations of indole at $298 \mathrm{~K}$ : (open circle) $\mathrm{H}_{2}-\mathrm{OG} 5 \mathrm{~A}$; (closed circle) $\mathrm{H}_{2}$-OG7A; (open square) $\mathrm{H}_{2}-\mathrm{OG} 10 \mathrm{~A}$; (closed square) $\mathrm{H}_{2}-\mathrm{OG} 15 \mathrm{~A}$; and (closed triangle) $\mathrm{H}_{2}-\mathrm{OG} 20 \mathrm{~A}$. 


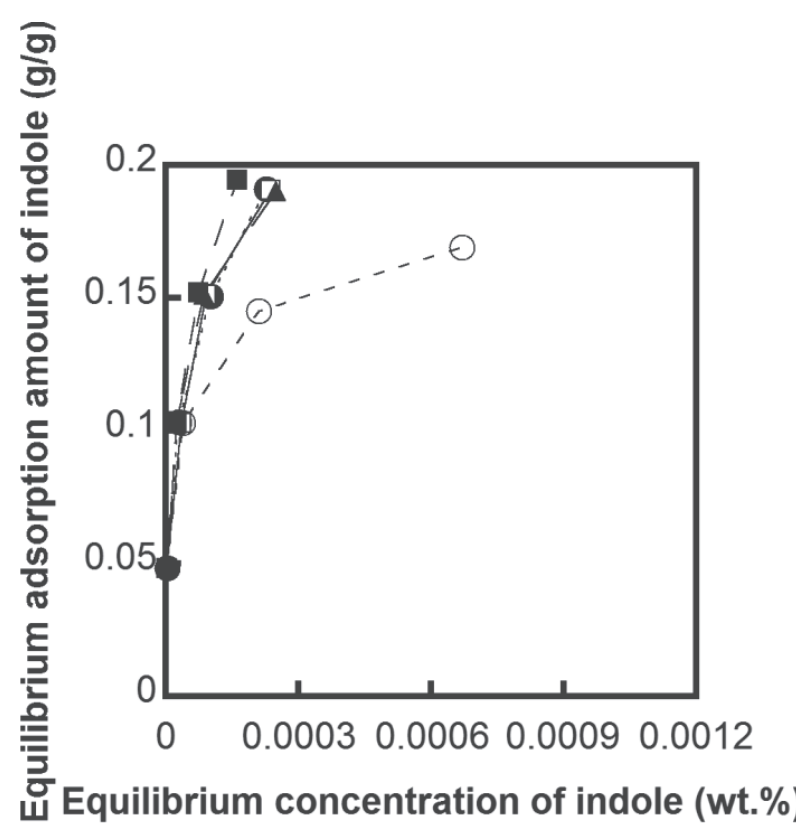

Fig. 2. Adsorption isotherms of indole on $\mathrm{H}_{2}-\mathrm{OG}$ series at $298 \mathrm{~K}$ : (open circle) $\mathrm{H}_{2}-\mathrm{OG} 5 \mathrm{~A}$; (closed circle) $\mathrm{H}_{2}$-OG7A; (open square) $\mathrm{H}_{2}$-OG10A; (closed square) $\mathrm{H}_{2}$-OG15A; (closed triangle) $\mathrm{H}_{2}-\mathrm{OG} 20 \mathrm{~A}$.

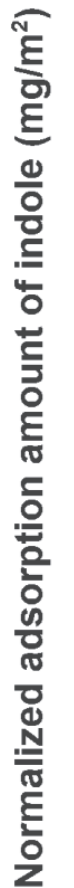

0.25

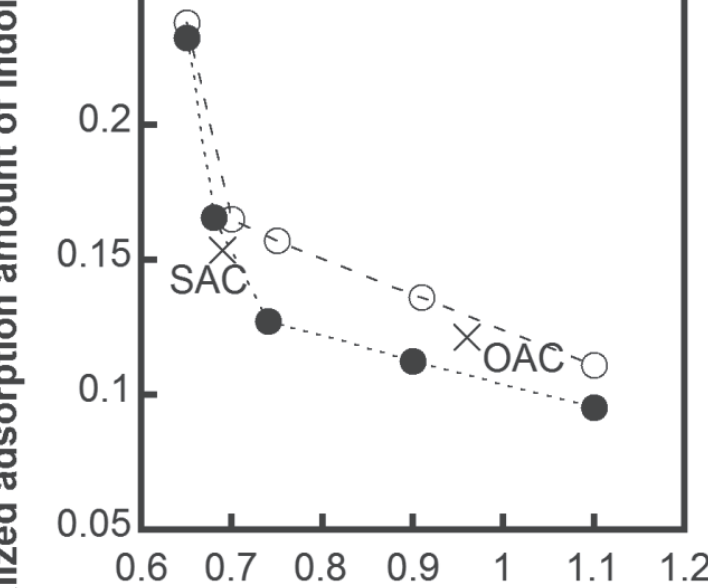

Average micropore width, $w_{\text {micro }}(\mathrm{nm})$

Fig. 3. Relationship between average micropore width and saturated adsorption amount of indole per unit surface area for (open circle) $\mathrm{H}_{2}-\mathrm{OG}$ series, (closed circle) OG series, and (cross) spherical activated carbons.

Basically, the adsorption amount of indole at the same equilibrium concentration became larger with increasing of specific surface area and total pore volume from $\mathrm{H}_{2}$-OG5A to $\mathrm{H}_{2}$-OG15A. However, $\mathrm{H}_{2}$-OG20A showed

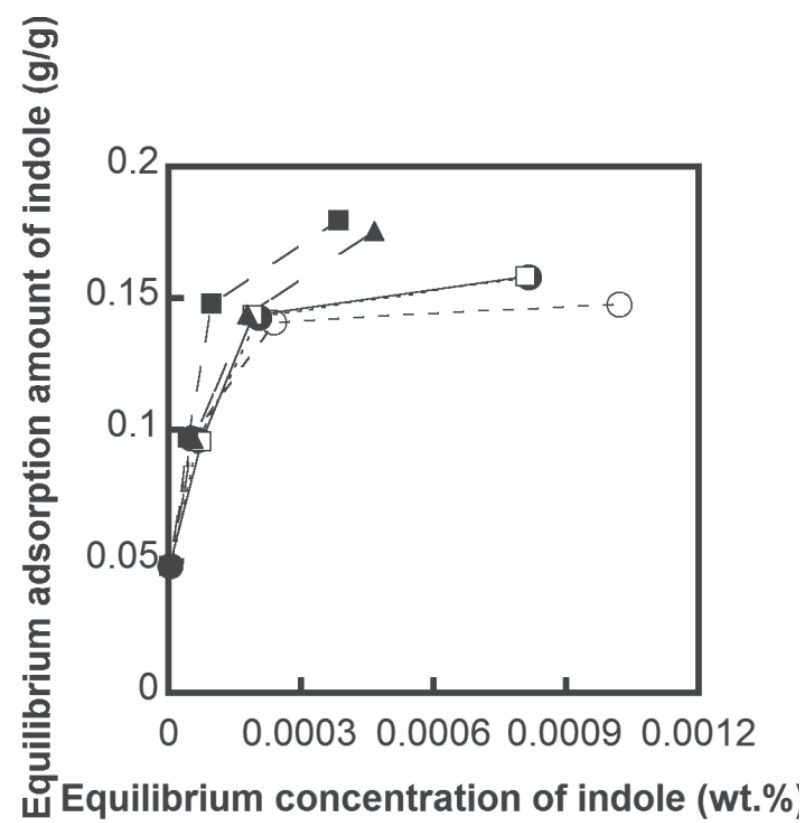

Fig. 4. Adsorption isotherms of indole on OG series at $298 \mathrm{~K}$ : (open circle) OG5A; (closed circle) OG7A; (open square) OG10A; (closed square) OG15A; (closed triangle) OG20A.

the apparently lower adsorption capacity than $\mathrm{H}_{2}$-OG15A, suggesting that the micropores of $\mathrm{H}_{2}$-OG20A were too wide for the indole molecules to be adsorbed efficiently, namely an overlapping of potential curves from pore walls was considered to be insufficient to provide deep and effective adsorption potentials for the indole molecules. In Figure 3, a relationship between the average micropore width, $\mathbf{w}_{\text {micro, }}$, and the saturated adsorption amount of indole per unit surface area (normalized adsorption amount of indole) for the $\mathrm{H}_{2}-\mathrm{OG}$ series is shown. Here, the normalized adsorption amounts of indole were calculated using the saturated adsorption amount of indole estimated by the Langmuir analysis of the adsorption isotherm of indole at $298 \mathrm{~K}$ shown in Figure 2 and the specific surface area of micropores, $A_{\text {micro }}$, calculated by the $a_{\mathrm{S}}$-plot analysis of the $\mathrm{N}_{2}$ adsorption isotherms at $77 \mathrm{~K}$ (Table 1). A monotonic decrease of the normalized adsorption amount of indole with an increase of the micropore width indicates that narrower micropores work as more effective adsorption spaces for the indole molecules.

For the OG series with larger amounts of oxygen-containing functional groups, the indole adsorption capability (Fig. 4) was found to be lower and the adsorption rate (Fig. 5) was slower than the $\mathrm{H}_{2}$-OG series with less oxygen contents, especially at the higher initial concentration of indole, suggesting that oxygen-containing functional groups strongly interacted with polar indole molecules, and thus hindered and delayed further adsorptions of indole to deeper pore spaces. The diffusional hindrance of polar molecule in micropore of activated carbons with abundant surface 
functional groups has been reported ${ }^{13)}$. The diffusional inhibition effects were remarkable for the pores of $\mathrm{W}_{\text {micro }}$ $=0.65 \mathrm{~nm}$ (OG5A vs. $\mathrm{H}_{2}$-OG5A). In terms of the normalized adsorption amount of indole, a similar tendency was found for the $\mathrm{OG}$ series with the $\mathrm{H}_{2}-\mathrm{OG}$ series; the narrower the pore width, the higher the normalized adsorption amount of indole (Fig. 3). Apparently, a correlation curve between the average micropore size and the normalized adsorption amount of indole for the $\mathrm{OG}$ series was located inferior to that for the $\mathrm{H}_{2}$-OG series, confirming the diffusional inhibition effects by the oxygen-containing functional groups.

Taken together, for the indole adsorption, the suitable activated carbons were found to possess high surface area, narrow pores, and low amounts of surface functional groups. However, the optimum pore width seems to be about $0.70 \mathrm{~nm}$ for the indole adsorption not only from the adsorption capacity, but also from the adsorption rate.

The equilibrium indole adsorption amounts at each initial concentration, and thus indole adsorption isotherms, for OAC and SAC almost agreed with each other, though distinct differences were observed in the adsorption kinetics especially at the initial adsorption stage (Fig. 6). The observed different adsorption rates were considered to be due to different particle size of
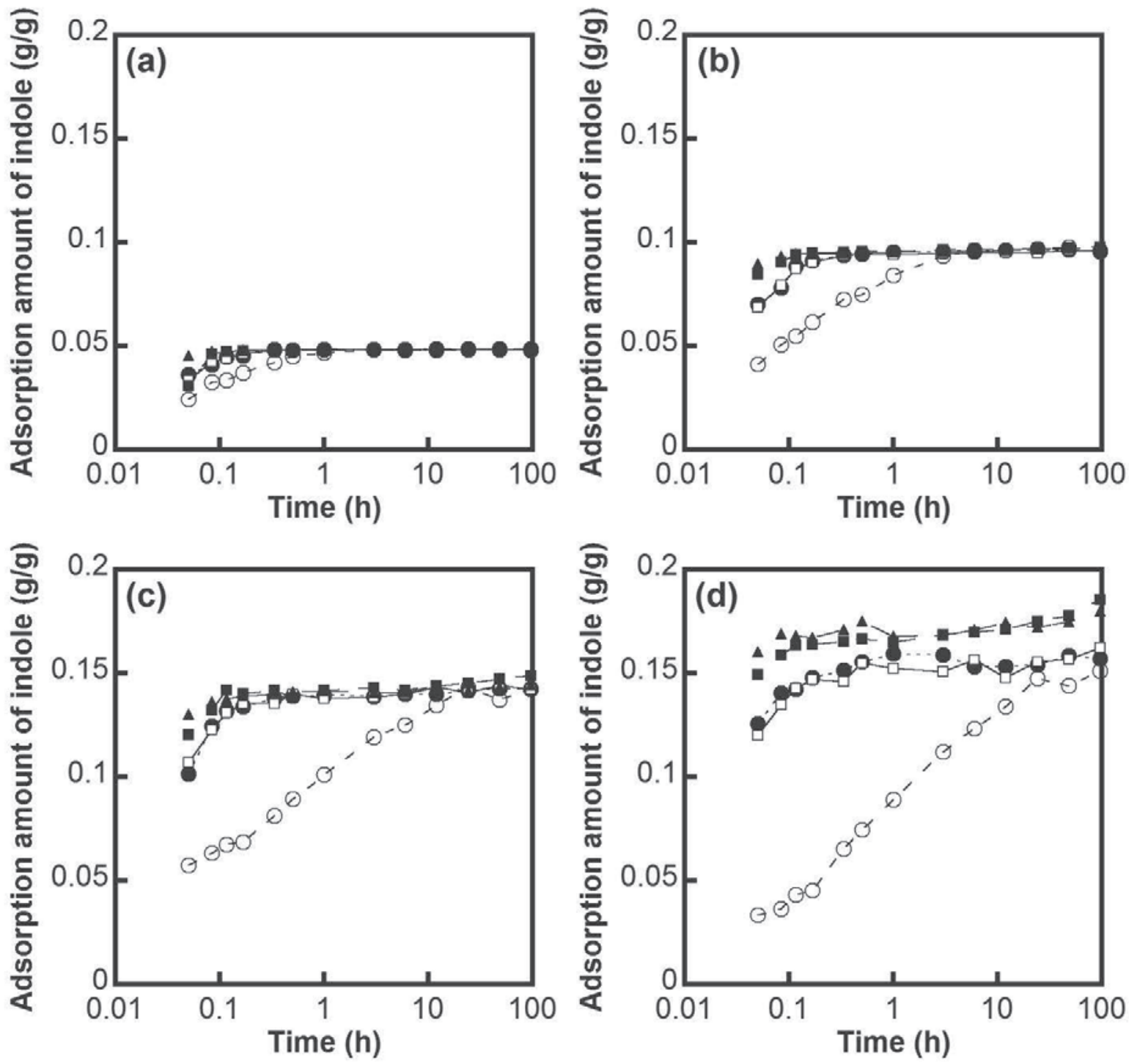

Fig. 5. Adsorption kinetic profiles of indole for OG series at (a) $0.001 \%$, (b) $0.002 \%$, (c) $0.003 \%$, and (d) $0.004 \%$ of initial concentrations of indole at $298 \mathrm{~K}$ : (open circle) OG5A; (closed circle) OG7A; (open square) OG10A; (closed square) OG15A; (closed triangle) OG20A. 
OAC and SAC; it would take longer time for the indole solution to diffuse into and saturate the inner parts of the OAC particles having larger particle size as compared to SAC with smaller particle size. This is likely because, as compared with the results for the activated carbon fibers (OG and $\mathrm{H}_{2}-\mathrm{OG}$ series) of $10-20 \mu \mathrm{m}$ in the fiber diameter ${ }^{10)}$, the adsorption rates were slower for spherical activated carbons (OAC and SAC) of 100-300 $\mu \mathrm{m}$ in diameter (Figs. 1 and 5 vs. Fig. 6). The indole adsorption amounts per unit surface area for OAC and SAC are also plotted in Figure 3. Although SAC has both micropores and mesopores, the micropore surface area was tentatively used for the plotting. As shown in Figure 3, a point for SAC calculated using the micropore surface area was almost on the correlation curve for the
OG series, but the point deviated from the correlation curve when the mesopore surface area was taken into account in the calculation of the normalized adsorption amount of indole. This suggests that mesopores of SAC seemed not to work as effective adsorption sites for the indole molecules. For OAC, on the other hand, a point was found near the correlation curve for the $\mathrm{H}_{2}$-OG series. The lower amounts of the oxygen-containing functional groups for $\mathrm{OAC}$ were considered to reduce the diffusional inhibition effects as found for the $\mathrm{H}_{2}$-OG series.

The adsorption kinetic measurements of amylase showed very slow adsorption rate for all OG series and spherical activated carbon samples (Fig. 7). The amylase molecules are known to take various structural forms,
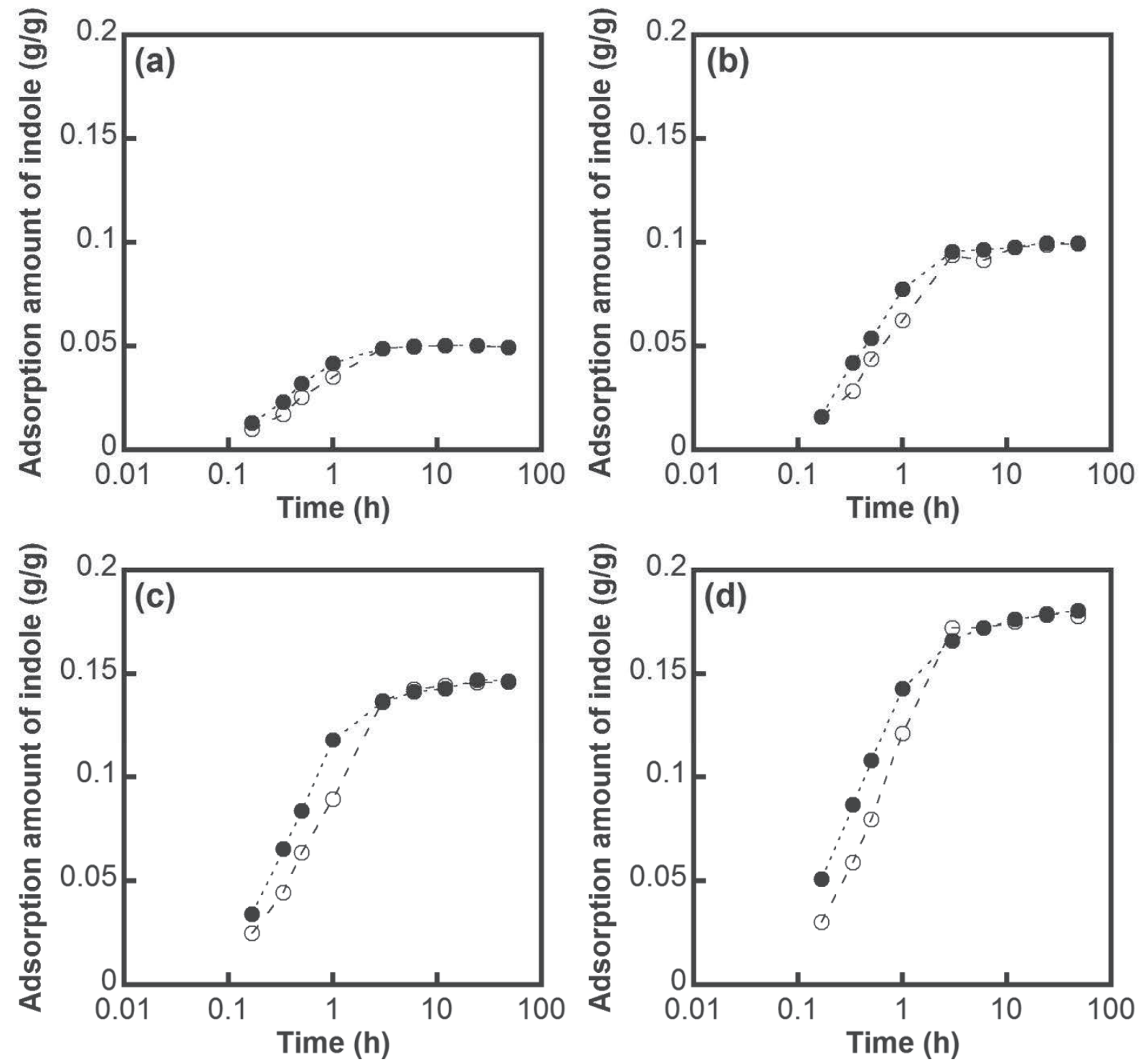

Fig. 6. Adsorption kinetic profiles of indole for spherical activated carbons at (a) $0.001 \%$, (b) $0.002 \%$, (c) $0.003 \%$, and (d) $0.004 \%$ of initial concentrations of indole at $298 \mathrm{~K}$ : (open circle) OAC; (closed circle) SAC. 
depending on the environment or surrounding/contacting materials ${ }^{14)}$. Considering the large molecular size of amylase, structural transformation should be necessary to diffuse into micropores, and thus longer periods were required to be adsorbed. Although the adsorptions were still in progress at $12 \mathrm{~h}$ after the introduction of amylase, we tentatively estimated removal amounts of amylase as a ratio between the amylase concentration in the filtrate at $12 \mathrm{~h}$ and the initial concentration ${ }^{15)}$, and found to be less than $10 \%$ for all samples. In detail, the smaller the pore size, the less the removal amounts of amylase. It was also found that no distinct differences in the
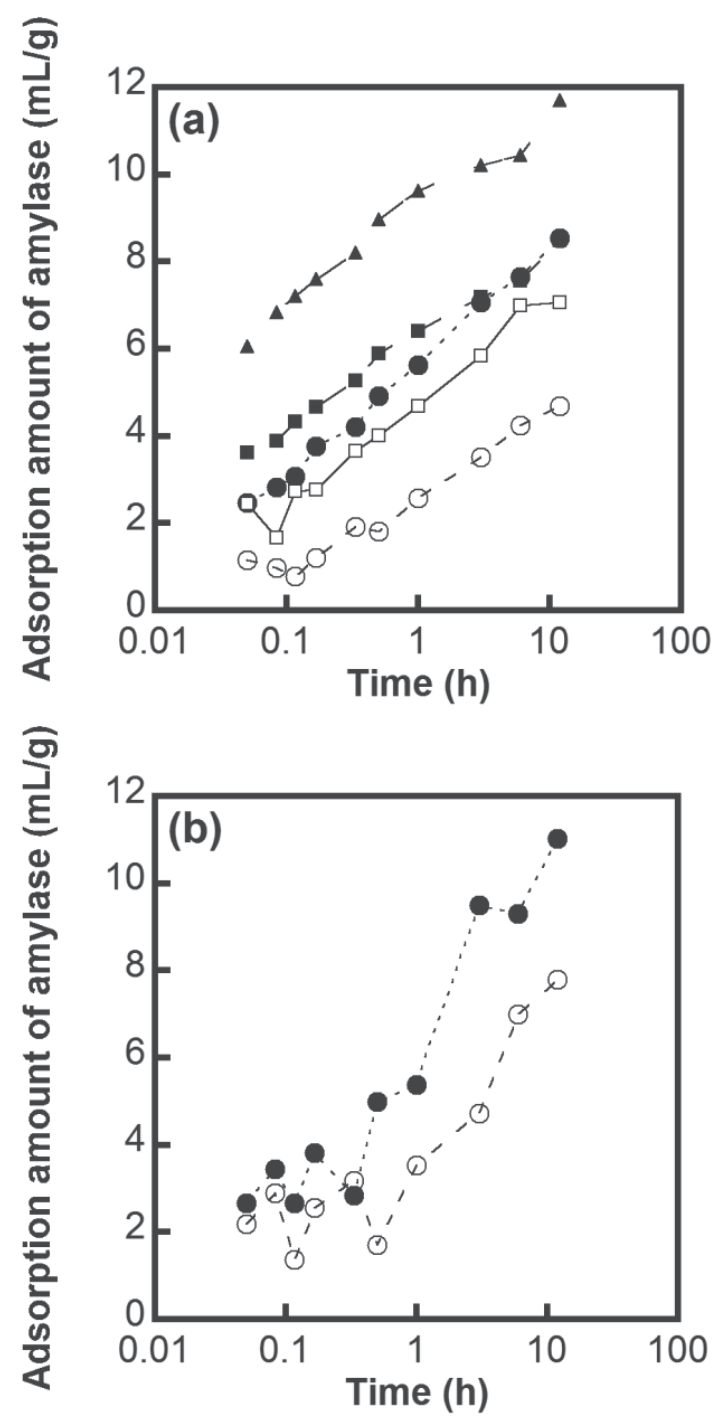

Fig. 7. Adsorption kinetic profiles of amylase for OG series and spherical activated carbons at 298 K. (a) OG series: (open circle) OG5A; (closed circle) OG7A; (open square) OG10A; (closed square) OG15A; (closed triangle) OG20A, (b) spherical activated carbons: (open circle) OAC; (closed circle) SAC. adsorption rate and capacity of amylase were observed for SAC, which has both micropores and mesopores, suggesting that carbonaceous pores would not be suitable adsorption spaces for the amylase molecules (Fig. 7b).

\section{Conclusions}

Both pore size and surface properties of the activated carbons were found to strongly influence on the indole adsorption capacity and rate; the requisites of the carbon adsorbents for effective removals of indole are high surface area, narrow pore size of about $0.70 \mathrm{~nm}$, and low amounts of the surface functional groups in the case of the single-component adsorption conditions. On the other hand, the adsorption rate of amylase was much slower than that of indole, and the adsorption amounts were limited. Thus, as the oral applications to selectively remove the wastes in the body such as indole but not useful molecules such as amylase, it was concluded that the activated carbons having abundant micropores of about $0.70 \mathrm{~nm}$ in size and hydrophobic surfaces are suitable.

\section{Acknowledgements}

We thank to Osaka Gas Co., Ltd. and Puresphere Co., Ltd. for providing samples. The financial support from the Korea Environmental Industry and Technology Institute is gratefully acknowledged. This work was also supported by the Global-Centre of Excellence in Novel Carbon Resource Sciences, Kyushu University.

\section{References and Notes}

1) C.M. Swartz and A. Sherman, J. Clin. Psychopharmacol., 4, 336 (1984).

2) R.F. Fricke and J. Jorge, J . Toxicol. Clin. Toxicol., 28, 421 (1990).

3) T. Tsujikawa, Y. Araki, J. Makino, K. Uda, T. Ihara, M. Sasaki, Y. Fujiyama and T. Bamba, J. Gastroenterol., 35, 296 (2000).

4) K. Koide, M. Sano, F. Takeda, T. Momose, S. Koshikawa and T. Akizawa, Biomater. Artif. cells Immobil. Biotechnol., 19, 147 (1991).

5) T. Akizawa, K. Koide, S. Koshikawa, Kidney Dialysis, 45, 373 (1998).

6) T. Sanaka, T. Akizawa, K. Koide and S. Koshikawa, Ther. A pher. Dial., 8, 232 (2004).

7) www.kureha.co.jp/ir/library/english/pdf/060125eng.p df

8) P. Gaudreault, Clin. Pediatr. Emerg. Med., 6, 76 (2005).

9) P.A. Chyka, D. Seger, E.P. Krenzelok, J.A. Vale, Clin. 
Toxicol., 43, 61 (2005).

10)N. Shiratori, K.J. Lee, J. Miyawaki, S.H. Hong, I. Mochida, B. An, K. Yokogawa, J. Jang and S.H. Yoon, Langmuir, 25, 7631 (2009).

11)K.S.W. Sing, Carbon, 27, 5 (1989).

12)K. Kaneko, C. Ishii, M. Ruike and H. Kuwabara, Carbon, 30, 1075 (1992).

13)H.-S. Kil, T. Kim, K. Hata, K. Ideta, T. Ohba, H. Kanoh, I. Mochida, S.-H. Yoon and J. Miyawaki, Appl. Them. Eng., 72, 160 (2014).

14)A.A. Anisimov, I.F. Aleksandrova, K.A. Iudina, S.K. Abzeev, M.O. Kondrateva and G.G. Beresieva, Biochemistry-M oscow, 42, 1748 (1977).

15)In our experimental conditions, putrefactions of amylase aqueous solution started at time longer than $12 \mathrm{~h}$ after the introduction of the porous carbon samples, which cause significant errors in measured absorption values using the UVvisNIR spectroscopy. Therefore, in this study, we set measurement times up to $12 \mathrm{~h}$ for the amylase adsorption experiments. 